\title{
DEMANDA DE PRODUTOS FLORESTAIS NÃO MADEIREIROS: O CASO DO AÇAÍ E DA CASTANHA-DO-PARÁ
}

\author{
Wilnália Souza Garcia* \\ Antonio Cordeiro de Santana** \\ Ana Karlla Magalhães Nogueira*** \\ Cyntia Meireles Martins****
}

RESUMO: O objetivo do trabalho foi estimar as relações de demanda dos produtos florestais não madeireiros açaí e castanha-do-Pará, localizados nas seis mesorregiões do Estado do Pará, a partir da estimativa dos parâmetros das equações de demandas agregadas marshallianas, a fim de estimar as elasticidades e analisar as implicações para ampliar a eficácia das políticas de ICMS e preços mínimos e de comercialização. O modelo especificado foi um painel de dados, estimado pelo método de Mínimos Quadrados Generalizados em dois Estágios (MQG2E). Os resultados revelaram que o fruto do açaí extrativo é um bem inferior à sua demanda, sendo inelástica a preço. A castanha foi caracterizada como produto substituto do açaí e os produtos da lavoura temporária um bem complementar do açaí. A demanda de castanha foi inelástica e classificada como um bem normal. Por fim, o imposto sobre circulação de mercadorias e serviços apresentou impacto significativo na redução das demandas de açaí e da castanha.

PALAVRAS-CHAVE: Amazônia; Mercado; Métodos quantitativos; Produtos extrativos.

\section{DEMAND OF NON-TIMBER FOREST PRODUCTS: AÇAÍ AND BRAZIL NUT}

ABSTRACT: Demand for non-timber forest products, such as the açaí and Brasil nut, in the six meso-regions of the state of Pará, Brazil, is assessed through estimates of parameters of aggregated Marshallian demand equations. Elasticity is estimated and the implications are analyzed to amplify ICMS policies, minimum prices and

\footnotetext{
Docente na Universidade Federal Rural da Amazônia (UFRA), Brasil.

** Doutor em Economia. Docente na Universidade Federal Rural da Amazônia (UFRA), Brasil.

*** Docente na Universidade Federal Rural da Amazônia (UFRA), Brasil.

${ }^{* * * *}$ Doutorado em Ciências Agrárias. Professora da Universidade Federal Rural da Amazônia (UFRA), Brasil. E-mail: cyntiamei@hotmail.com
} 
commercialization. Model consisted of a data panel estimated by the Generalized Two Stage Least Squares (MQG2E). Results revealed that the extract from the açaí fruit is lower than demand, with non-elastic price. The Brazil nut was characterized as a substitute product for the açaí, whilst products of temporary labor were complementary goods to açaí. Demand for nuts was non-elastic and classified as normal. Tax on goods and service movement had a significant impact in the decrease of açaí and nut demands.

KEY WORDS: Amazon, Market; Quantitative methods; Extraction products.

\section{INTRODUÇÃO}

O mercado de produtos florestais não madeireiros (PFNM) vem ganhando cada vez mais importância social e econômica com o aumento do consumo. Na busca por alternativas econômicas para o desenvolvimento sustentável da Amazônia, o extrativismo de PFNM foi considerado como promissor, devido ao baixo impacto ecológico dessa atividade, aliado à existência de mercados potenciais.

No Estado do Pará, os PFNM que apresentam maiores volumes da produção exclusivamente do extrativismo são o açaí (Euterpe oleracea) e a castanha-do-Pará (Bertbolletia excelsa) por serem produtos que ganharam abrangência nos mercados nacional e internacional (SANTANA, 2016).

Em 2012, a produção extrativa do açaí e da castanha-do-Pará no Estado do Pará foi de 110.940 t e 10.452 t, respectivamente. Essa produção representou 69,44\% (R\$260.768,72 mil) e 24,56\% (R\$18.790,64 mil), respectivamente, do valor da produção total da Amazônia Legal (IBGE, 2015). No período da pesquisa (2000 a 2012), a produção de açaí e castanha evoluiu a uma taxa de $2,72 \%$ ao ano e $4,49 \%$ ao ano, respectivamente, no Estado do Pará (SANTANA, 2016).

O açaí extrativo representa, aproximadamente, 98\% da produção de PFNM do Estado do Pará, com alta importância socioeconômica para a sociedade paraense (NOGUEIRA; SANTANA; GARCIA, 2013). O fruto faz parte da dieta alimentar da população paraense, em especial dos ribeirinhos (SANTANA; GOMES, 2005), que consomem o produto processado na forma de polpa e comercializam o fruto excedente.

A castanha-do-Pará, por sua vez, é uma amêndoa oriunda da castanheira, 
árvore nativa da Amazônia, que apresenta valor econômico pela versatilidade no consumo in natura e na culinária, por meio da produção de óleos, leite e farinha, com alto valor nutritivo (SILVA et al., 2013; SANTANA, 2015; SANTANA et al., 2015; SANTANA, 2016).

A exploração extrativa da castanha após o declínio da exploração de borracha tornou-se a principal atividade econômica na região amazônica (SANTANA, 2015) e, atualmente, continua importante para o sustento das populações tradicionais de índios, quilombolas e ribeirinhos que dependem do extrativismo destes produtos nas unidades de conservação da Amazônia.

Contudo, a despeito da importância desses produtos, os agentes com interesse em aproveitar a expansão do mercado continuam praticando um extrativismo predatório e oferecendo produtos de baixa qualidade e de baixo valor comercial. Não se compreende até que ponto a ausência de boas práticas de coleta dos produtos e a entrega em mais de $78 \%$ da produção para atravessadores contribui para a sobrevivência das famílias e a sustentabilidade do extrativismo (SANTANA, 2015; SANTANA, 2016).

O futuro da atividade extrativista da castanha-do-Pará e do açaí depende de um conjunto de ações que vai desde a organização dos produtores para criar escala e poder de negociação, da utilização de boas práticas de produção para aumentar a produtividade e a qualidade dos produtos, da obtenção de informação sobre a comercialização, preços e quantidades demandadas e ofertadas e da inserção de tais produtos nos diversos segmentos de mercado nacional e internacional (SANTANA, 2016). Ainda, Saha e Sundriyal (2012) destacam que a extração de PFNMs é considerada a melhor e mais viável estratégia de conservação para áreas ricas em biodiversidade como o caso do Estado do Pará.

Nestes termos Araújo, Souza e Pimenta (2015) acentuam que essas ações correspondem a uma inovação no qual tanto o meio ambiente, quanto os consumidores e os produtores podem se beneficiar. Segundo os mesmos autores essa inovação passa a ser chamada "cadeia de suprimento verde", em que se passa a considerar os aspectos ambientais de uma cadeia de suprimentos, considerando a pressão da sociedade, o controle dos resíduos sólidos, o uso racional dos recursos naturais e a legislação ambiental (ARAÚJO; SOUZA; PIMENTA, 2015).

Neste contexto intenciona-se responder ao seguinte questionamento: Qual 
a contribuição das variáveis econômicas (quantidade, preço, PIB per capita e ICMS) para explicar a dinâmica do mercado destes produtos e orientar as decisões dos extrativistas de açaí fruto e castanha-do-Pará com casca das mesorregiões do Estado do Pará?

Sendo assim, o objetivo deste trabalho foi ampliar o conhecimento sobre o mercado destes produtos a partir da estimação dos parâmetros das equações de demandas agregadas marshallianas para as seis microrregiões do Estado do Pará, estimar as elasticidades e analisar as implicações para ampliar a eficácia das políticas de ICMS e preços mínimos e de comercialização da castanha com casca e do açaí fruto. Como a produção está restrita ao estoque dos recursos naturais das unidades de conservação a oferta torna-se, conforme Santana (2015) e Santana et al. (2016; 2017), perfeitamente inelástica em curto prazo, de modo que os preços variam em função das alterações na demanda.

\subsection{FUNDAMENTAÇÃO TEÓRICA DO TRABALHO}

De acordo com Marshall (1982), a demanda reflete a quantidade dos bens e serviços que os consumidores estão dispostos e podem efetivar a compra, sujeitos aos preços praticados no mercado em dado período de tempo, assumindo que as demais variáveis que afetam a demanda permanecem constantes. Portanto, o consumidor tende a alocar sua renda na aquisição de uma cesta de produtos e serviços, com preços relativos diferenciados, de modo a maximizar sua satisfação ou utilidade. Assim, a demanda individual de cada produto é derivada da otimização da função utilidade sujeita à restrição de renda. Logo, tem-se que a utilidade marginal é a quantidade demandada do bem ou serviço em função do preço do produto e da renda do consumidor (SANTANA, 1999; VARIAN, 2012).

Com relação aos efeitos do preço e da renda sobre as quantidades demandadas do produto, tem-se que mudanças nos preços do produto levam ao consumidor racional reduzir as quantidades demandadas, como definido na Lei da Demanda de Marshall (1982), que revela que as quantidades demandadas tendem a variar inversamente aos preços. Por outro lado, um aumento na renda do consumidor tende a induzir incrementos na demanda e, por sua vez, nas quantidades de equilíbrio do mercado, em sintonia com a Lei de Engel (PINDYCK; RUBINFELD, 2010). Para a aná- 
lise de comportamento destas variáveis sobre as quantidades demandadas, definem-se as elasticidade-preço e elasticidade-renda do produto. A elasticidade-preço capta a mudança percentual nas quantidades em resposta às mudanças percentuais ocorridas nos preços e a elasticidade-renda mede a variação percentual nas quantidades demandadas que resultam de alterações percentuais na renda dos consumidores.

$\mathrm{Na}$ análise empírica da demanda, além do preço e da renda, dependendo da disponibilidade de dados e das peculiaridades do mercado, levam-se em consideração os preços de outros produtos relacionados ao consumo (SANTANA, 2005; PINDYCK; RUBINFELD, 2010; VARIAN, 2012), assim como a qualidade do produto, nível de educação do consumidor e políticas reguladoras do consumo (SANTANA et al., 2017a), de modo que mudanças individuais nessas variáveis produzem deslocamentos na demanda e, por conseguinte, nas quantidades demandadas em dado período do tempo. A relação entre o comportamento das quantidades demandadas de um produto em relação a mudanças nos preços de outros produtos relacionados no consumo, com vistas a maximizar a satisfação dos consumidores, é conhecida como relação de substitutibilidade ou de complementaridade no consumo (SANTANA, 1999; VARIAN, 2012; PINDYCK; RUBINFELD, 2010; SANTANA et al., 2017b). Dois produtos são considerados substitutos quando a mudança no preço de um produto induz a alteração na quantidade demandada do outro produto na mesma direção e é captado pela elasticidade cruzada da demanda que capta a variação percentual entre uma alteração no preço de um produto sobre as quantidades demandadas de outro produto (VARIAN, 2012; PINDYCK; RUBINFELD, 2010; MANKIW, 2009). Assim, quando a elasticidade cruzada da demanda é positiva, tem-se que os produtos são substitutos e quando apresenta um valor negativo, diz-se que os produtos são complementares no consumo.

Com efeito, a demanda de mercado ou demanda agregada marshalliana dos produtos açaí fruto e castanha-do-Pará com casca, além do preço e renda, possui o leque de variáveis para incorporar produtos substitutos e complementares e variáveis de política que influenciam a demanda dos produtos. O açaí fruto e a castanha com casca são produtos do extrativismo e, neste nível do mercado, têm-se poucos produtos substitutos e, mesmo para estes como é o caso da bacaba para o açaí (SANTANA; COSTA, 2008), não se dispõe de série histórica. Para a castanha com casca, conforme Santana e Khan (1992), Santana (2015) e Santana et al. (2016), seria a castanha de 
caju, que também não tem série de dados para as mesorregiões do Estado do Pará. Para tanto, construiu-se um índice de preços dos produtos de lavoura temporária (arroz, feijão, milho e mandioca), dada a disponibilidade de informações para o período analisado em todas as mesorregiões, para representar produtos substitutos ou complementares para os consumidores da castanha com casca e do açaí fruto.

O ponto fundamental deste trabalho está configurado no fato de que no mercado do fruto de açaí e da castanha-do-Pará com casca em nível do extrativista, a demanda é formada por atravessadores, dado que $94,79 \%$ e 77,2\%, respectivamente, da produção de açaí e castanha são adquiridas por esses agentes da comercialização (SANTANA, 2016). A venda direta aos consumidores representa apenas 3,5\% e 7,31\%, respectivamente para o açaí fruto e a castanha com casca. O diferencial é que o açaí fruto não é consumido diretamente e sim sua polpa. Da mesma forma, a castanha com casca negociada entre extrativistas e os atravessadores, no local das reservas extrativistas, a castanha ainda não está seca e pronta para a venda no mercado atacadista e/ou varejista. Portanto, a demanda é configurada pelos agentes intermediários da comercialização que atuam como autônomos e/ou a serviços de cooperativas e/ou agroindústrias (SANTANA, 2016; KRAG et al., 2016). Estes agentes têm conhecimento do mercado e adquirem quantidades pequenas, de modo que a ação isolada de cada um deles não influencia no preço de equilíbrio do mercado (NOGUEIRA et al., 2013; SANTANA et al., 2015; SANTANA et al., 2017a). Pelas características do mercado destes produtos de concorrência pura, alta sazonalidade, inelasticidade-preço (SANTANA; COSTA, 2008; SANTANA, 2013) e demanda efetivada por agentes intermediários da comercialização que visam maximizar a satisfação com a cesta de produtos que adquire e transporta (SANTANA, 2016) pode-se encontrar relações de complementaridade ou de substituição entre açaí e castanha e entre estes e produtos das lavouras temporárias para os destes produtos, considerando a demanda agregada marshalliana.

Adicionalmente, a influência de variáveis de políticas que regulam a demanda destes produtos e que se dispõe de informação, foi analisado a partir da variável ICMS, que incide sobre os preços desses itens e, por essa via, afeta a decisão dos intermediários da comercialização de adquiri-los, dado que respondem pela maior proporção da demanda desses produtos (SANTANA et al., 2015). Portanto, um incremento na alíquota do imposto e/ou aumento da fiscalização por parte dos agentes da 
Secretaria de Fazenda tende a diminuir a quantidade demandada desses produtos.

Com relação à oferta, assumiu-se, conforme Santana et al. (2017), que as ofertas do açaí fruto e da castanha com casca do extrativismo como perfeitamente inelásticas, dado que os estoques de açaizais nativos e de castanheiras estão definidos e totalmente explorados. Portanto, a mudança na oferta depende dos cultivos racionais em curso em duas mesorregiões do Estado do Pará e cujo comportamento foi recentemente estudado por Nogueira e Santana (2016). No caso da castanha com casca, estudo recente de Santana et al. (2016) comprova que a oferta de castanha com casca no Pará é perfeitamente inelástica.

Neste caso, os preços do açaí fruto e da castanha com casca são formados pelos movimentos da demanda por tais produtos. Nos últimos anos, a demanda por açaí fruto, conforme Santana e Costa (2008), Nogueira, Santana e Garcia (2013), Santana et al. (2014) e Nogueira e Santana (2017), tem evoluído rapidamente e estimulou a utilização de práticas de manejo e de plantio irrigado em terra firme com vistas a incrementar a oferta. No caso da castanha com casca, especificamente no Estado do Pará, a oferta continua estagnada, a ponto de perder importância relativa para os Estados do Acre e de Rondônia, que estão adotando formas de organização dos extrativistas em cooperativas e a produção está aumentando.

Neste contexto, o mercado de açaí fruto e da castanha-do-Pará com casca das mesorregiões paraenses no período analisado pode ser analisado com base no comportamento das decisões dos consumidores locais, que definem as demandas marshallianas agregadas por tais produtos como adequadas para as análises conjunturais e estruturais do comportamento do mercado desses produtos, no que tange à evolução do PIB per capita, do índice de preços das lavouras temporárias e do ICMS que produzem deslocamento na demanda e provocam variações dos preços de equilíbrio.

\section{MATERIAL E MÉTODOS}

\section{1 ÁREA DE ESTUDO E FONTE DE DADOS}

A área de pesquisa foi o Estado do Pará, considerando as seis mesorregiões 
em que o açaí fruto e a castanha-do-Pará com casca são produzidos. Estes produtos apresentam o maior volume de Produtos Florestais não Madeireiros (PFNM) oriundos do extrativismo e se conhece muito pouco sobre a demanda desses produtos, definida no local de produção por intermediários da comercialização, diante de uma oferta limitada pelo estoque remanescente das áreas de reserva.

O período do estudo compreende os anos de 2000 a 2012, perfazendo uma amostra de 78 observações extraídas de fontes oficiais disponíveis no Instituto Brasileiro de Geografia e Estatística (IBGE), referente a à produção agrícola municipal (quantidade e preço das lavouras temporárias), a extração vegetal e silvicultura sobre quantidades produzidas e preços dos produtos florestais não madeireiros (açaí fruto e castanha-do-Pará com casca). Do Instituto de Desenvolvimento Econômico, Social e Ambiental (IDESP) do Estado do Pará obteve-se o PIB per capita para as seis mesorregióes. Desde 1995, com o convênio firmado entre o IBGE e os governos estaduais, são disponibilizadas as estatísticas de PIB para os Estados. No Pará, o IDESP é que responde pela geração e disponibilização das estatísticas oficiais sobre suas atividades produtivas. A respeito do Imposto Sobre Circulação de Mercadorias e Serviços (ICMS) os dados oficiais são da Secretaria de Estado da Fazenda do Estado do Pará (SEFA-PA), que são reunidos e disponibilizados para a sociedade nas estatísticas do Estado do Pará organizados pelo IDESP ao longo do período analisado. Portanto, todas estas informações se referem a estatísticas oficiais do Pará, que foram organizadas e disponibilizadas pelo IDESP, órgão que responde pelos estudos socioeconômicos e ambientais.

Como a demanda em nível do extrativismo é definida pelos agentes intermediários da comercialização ou atravessadores, elegeu-se os produtos das lavouras temporárias (arroz, feijão, mandioca e milho) como de interesse desses agentes para definirem a cesta de produtos que orientam as decisões de compra. Para isto, construiu-se um índice de preços agregando esses quatro produtos para avaliar sua relação com as quantidades demandadas de açaí fruto e castanha com casca em nível de produtor. Com efeito, todas as variáveis monetárias foram deflacionadas pelo Índice Geral de Preços - Disponibilidade Interna, disponibilizados pela Fundação Getúlio Vargas.

A amostra de 78 observações (13 anos x 6 mesorregiões) foi estruturada na 
forma de dados em painel pela combinação das informações em séries temporais de 13 anos (2000 a 2012) com os dados de seção cruzada das seis mesorregiões do Estado do Pará. O software utilizado para estimar os parâmetros das equações de demanda agregada desses PFNM foi o Eviews7.

\subsection{MODELO ECONOMÉTRICO}

Com base na teoria microeconômica do consumidor apresentada na seção anterior, as equações de demanda dos PFNM foram especificadas em função do preço dos produtos de açaí fruto, castanha-do-Pará com casca; de um índice de preços representativo das lavouras temporárias comercializadas por atravessadores na área de estudo em conjunto com o açaí e a castanha; do imposto ICMS que incide na comercialização dos produtos e do PIB per capita, utilizado como proxy da variável renda. Com a equação de demanda agregada especificada dessa forma, espera-se obter uma relação inversa entre o preço e a quantidade demandada, visto que, com o aumento dos preços dos produtos, em geral, os consumidores tendem a diminuir a quantidade demandada dos respectivos produtos. Com relação à renda, espera-se uma relação direta entre variações na renda e nas quantidades demandadas dos produtos, por se tratarem de bens normais.

Em relação ao ICMS, espera-se uma relação inversa, pois, na medida em que o imposto sobe, o preço do produto tende a aumentar e, como consequência, a tendência dos consumidores é adquirir uma quantidade menor do produto.

Os mercados de açaí fruto e castanha-do-Pará com casca das mesorregiões paraenses apresentam características de concorrência pura (SANTANA et al., 2015), ou seja, existe um grande número de consumidores que individualmente adquire uma pequena quantidade desses produtos, de modo que suas decisões de compra não alteram os preços do produto. Estes produtos também são homogêneos em termos de qualidade, mesmo não sendo considerada a origem do produto, conforme percepção dos consumidores que, no caso, são os atravessadores. Além disso, em tese não há preferências específicas por um produto de um dado extrativista e nem existem barreiras que impeçam a entrada ou a saída desses agentes demandantes nos mercados de açaí fruto e castanha-do-Pará com casca no período de tempo ana- 
lisado.

As demandas agregadas marshallianas (SANTANA, 1999; SANTANA, 2005; SANTANA, 2017; SANTANA et al., 2017) de açaí fruto e de castanha-do-Pará com casca foram especificadas na forma estrutural da seguinte:

$$
\ln Q_{i j t}=\alpha+\delta_{1}+\beta_{1 j} \ln P A C_{i j t}+\beta_{2 j} \ln P C P_{i j t}+\beta_{3 j} \ln P I B P C_{i j t}+\beta_{4 j} \ln P L T_{i j t}+\beta_{5 j} \operatorname{lnICMS} S_{i j t}+\varepsilon_{i j t}
$$

\subsubsection{Variáveis endógenas}

$\ln Q_{i j t}$ é o logaritmo natural da quantidade coletada pelos extrativistas do produto $j$ ( $j=$ açaí fruto e castanha-do-Pará com casca) da mesorregião $i$, no período $t(t=2000, \ldots, 2012)$, medido em tonelada;

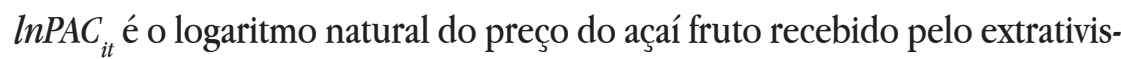
ta em $\mathrm{R} \$ /$ tonelada por mesorregião $i$, no período $t$;

$\ln P C P_{i t}$ é o logaritmo natural do preço da castanha-do-Pará com casca recebido pelo extrativista em $\mathrm{R} \$$ /tonelada por mesorregião $i$, no período $t$.

\subsubsection{Variáveis exógenas}

$\operatorname{lnPIBPC}_{i t}$ é o logaritmo natural do produto interno bruto per capita em $\mathrm{R} \$$ / hab./ano da mesorregião $i$, no período $t$;

$\operatorname{lnPLT}_{i t}$ é o logaritmo natural do índice de preços de Laspeyres para os produtos da lavoura temporária (arroz, feijão, mandioca e milho) da mesorregião $i$, no período $t$;

InICMS $_{i t}$ é o logaritmo natural do imposto sobre circulação de mercadorias e serviços em $\mathrm{R} \$$ da mesorregiões $i$, no período $t$.

\subsubsection{Parâmetros}

$\alpha$ é o valor do intercepto geral da equação, mantido igual para todos os cross-section;

é o parâmetro que representa o efeito longitudinal, considerado fixo no 
tempo;

$\beta$ é o vetor de parâmetros que medem o efeito das variáveis exógenas sobre as variáveis endógenas da equação de demanda;

$\varepsilon_{j}$ é o termo de erro aleatório, para a equação do produto $j$, com distribuição normal independente e identicamente distribuídos.

O modelo logarítmico foi especificado na forma de dados em painel (BALTAGI, 2013). As equações são super identificadas pelos critérios de ordem e de posto. Este modelo contribui para atenuar os problemas de colinearidade entre as variáveis por obter maior eficiência dos parâmetros. Também é adequado para analisar as mudanças na demanda entre as mesorregiões, dado que detectam e mensuram melhor os efeitos que não podem ser observados em séries temporais ou em modelos com dados em cortes transversais puros (BALTAGI, 2013).

Como o modelo foi especificado na forma logarítmica, os coeficientes já são as próprias elasticidades ${ }^{5}$ da demanda. Ou seja, os coeficientes $\beta_{11}, \beta_{21}, \beta_{31}, \beta_{41}$ e ${ }_{51}$ para a demanda de açaí são, respectivamente, as elasticidades-preço, elasticidade cruzada entre os produtos castanha com casca e açaí fruto, elasticidade-renda, elasticidade cruzada entre os produtos de lavouras temporárias e açaí e elasticidade-cruzada entre o ICMS e a demanda de açaí. Para a demanda de castanha-do-Pará com casca, os coeficientes $\beta_{12}, \beta_{22}, \beta_{32}, \beta_{42}$ e $\beta_{52}$ são, respectivamente, as elasticidades-preço, elasticidade cruzada entre os produtos açaí fruto e castanha com casca, elasticidade-renda, elasticidade cruzada entre os produtos de lavouras temporárias e castanha e elasticidade-cruzada entre o ICMS e a demanda de castanha. Portanto, a elasticidade-preço reflete ajustes entre quantidades e preços que ocorrem ao longo da linha de demanda e a mudança nas demais variáveis produzem deslocamentos na linha de demanda e, por sua vez, nas quantidades demandadas de equilíbrio do mercado (MARSHALL, 1982; SANTANA, 2005; MANKIW, 2009; PINDYCK; RUBINFELD, 2010; VARIAN, 2012).

Neste trabalho, os parâmetros do modelo especificado com dados em painel foram estimados por MQG2E usando a estimativa da matriz de variância residual com efeitos fixos. O modelo de efeito fixo foi escolhido pelo fato de que os dados são oriundos de mesorregiões fixas e a aferição foi realizada pelo teste de Hausman,

5 No modelo linear $\mathrm{Q}=\mathrm{A}+\mathrm{BP}$, a elasticidade preço é dada por: e no modelo logarítmico $\ln \mathrm{Q}=\ln \mathrm{A}+\mathrm{B}$ $\ln \mathrm{P}$, o coeficiente B é a elasticidade. Assim, . 
conforme Baltagi (2013). Assim, o modelo é um painel de dados equilibrado com efeitos fixos, inclusive mantendo o mesmo intercepto, com 13 observações (2000 a 2012) de seis mesorregiões, perfazendo um total de 78 observações.

\section{RESULTADO E DISCUSSÃO}

\subsection{A DEMANDA DE AÇAÍ}

Os resultados estimados do modelo de açaí estão na Tabela 1. Os sinais dos parâmetros estão de acordo com as hipóteses estabelecidas pela teoria do consumidor apresentada no referencial teórico. As estatísticas apresentaram-se diferentes de zero a $1 \%$ de probabilidade de erro de rejeitar a hipótese nula de que as variáveis não influenciam as quantidades demandadas. O coeficiente associado à variável preço do açaí fruto apresentou sinal negativo, indicando uma relação inversa com a quantidade demandada desse produto. $\mathrm{O}$ parâmetro associado à variável renda apresentou uma relação direta com a demanda, caracterizando o fruto de açaí como um bem normal. O coeficiente ligado à variável ICMS apresentou sinal negativo, mostrando uma relação inversa com a demanda e indicando que quanto maior o imposto, menor será a quantidade demandada de açaí pelos intermediários da comercialização que atuam nos mercados das mesorregiões do Estado do Pará.

O coeficiente de determinação ajustado para graus de liberdade indicou que $63,75 \%$ das variações nas quantidades demandadas de açaí fruto das mesorregiões do Estado do Pará, no período de 2000/12, foram explicadas diretamente por variações simultâneas no preço do açaí fruto, da castanha-do-Pará com casca, do índice dos preços de produtos da lavoura temporária, da renda e do ICMS. A estatística F, igual a 10,32, apresentou-se significativa a $1 \%$ de probabilidade de erro de rejeitar a hipótese nula, atestando a adequação do modelo proposto ao fenômeno estudado. Com efeito, a estatística $J$ de Hansen, igual a 0,2975, confirmou a hipótese nula de que o vetor de variáveis exógenas e instrumentais é ortogonal aos erros e que o modelo está corretamente especificado. A estatística de Durbin Watson indicou ausência de autocorrelação serial positiva de primeira ordem nos resíduos. Portanto, em termos gerais, tem-se que os resultados do modelo estimado são consistentes 
para representar a demanda do açaí fruto das mesorregiões do Pará.

Tabela 1. Resultados da equação de demanda de açaí fruto no Estado do Pará

\begin{tabular}{|c|c|c|c|c|}
\hline \multicolumn{5}{|c|}{ Variável Dependente : $\ln (\mathrm{QAC})$} \\
\hline Variável & Coeficientes & Desvio Padrão & Estatística - t & $\begin{array}{l}\text { Probabili- } \\
\text { dade }\end{array}$ \\
\hline Constante & $36,1856 * *$ & 2,93216 & 12,34091 & 0,0000 \\
\hline ln Preço açaí (PAC) & $-0,52768$ & 0,24964 & $-2,11376$ & 0,0383 \\
\hline ln Preço castanha (PCP) & $0,42941^{*}$ & 0,20125 & 2,13371 & 0,0366 \\
\hline In Renda & $0,49379 *$ & 0,23872 & 2,06849 & 0,0425 \\
\hline In Preço Lav. Temporária & $-0,54102 * *$ & 0,20142 & $-2,68689$ & 0,0091 \\
\hline $\ln$ ICMS & $-0,62267 * *$ & 0,19294 & $-3,22727$ & 0,0019 \\
\hline R-quadrado ajustado & 0,6375 & \multicolumn{2}{|c|}{ Média variavel depen } & 8,1726 \\
\hline Estatística - F & 10,3281 & \multicolumn{2}{|c|}{ Desv.p. variavel depend } & 1,8756 \\
\hline Prob. (Estatística - F) & 0.0000 & \multicolumn{2}{|c|}{ Estatist. Durbin-Watson } & 1,764 \\
\hline
\end{tabular}

Fonte: Dados da pesquisa. **Significativo a $1,0 \%$; *Significativo a 5,0\%.

Como o modelo de demanda do açaí fruto foi especificado na forma logarítmica, as estimativas dos parâmetros podem ser interpretadas diretamente como elasticidades, que indicam a reação percentual nas quantidades demandadas do produto em resposta a uma variação percentual na variável independente. Assim, a elasticidade-preço foi igual a $-0,5276$, indicando que as quantidades demandadas tendem a diminuir $5,276 \%$ em resposta a aumentos de $10 \%$ nos preços do produto ao longo do período analisado, caracterizando a demanda de açaí fruto como inelástica a preço. Portanto, os consumidores são pouco sensíveis à variação de preço do açaí fruto, ou seja, uma pequena variação na quantidade demandada requer uma grande alteração no preço do açaí fruto, caso contrário tudo continua como se a situação do mercado operasse em condições normais, na percepção dos intermediários da comercialização que exercem efetivamente a demanda do produto. Apenas a bacaba (Oenocarpus bacaba Mart) se apresenta como substituto do açaí, mas além de ter pouca expressão no mercado e na preferência dos consumidores, a produção ocorre em período diferente da do açaí fruto e não dispõe de estatísticas de quantidade 
produzida e comercializada (SANTANA; COSTA, 2008; NOGUEIRA; SANTANA, 2009).

No período de 1985 a 2003, Santana e Gomes (2005) estimaram a elasticidade-preço da demanda de fruto de açaí em nível do extrativista de $-0,515$. No período de 1994 a 2009, Nogueira et al. (2013) encontraram uma elasticidade-preço da demanda igual a $-0,779$, mostrando que a reação dos agentes intermediários da comercialização, que exercem a demanda do fruto de açaí em nível do extrativista, se tornou mais elástica ao longo do tempo, dadas as mudanças que estão se processando nos níveis de mercado de atacado e de varejo pela polpa de açaí e que estão gerando incremento na demanda por fruto. $\mathrm{O}$ preço aumentou por causa dessa pressão de demanda por polpa de açaí nos mercados das demais unidades da federação e internacional (NOGUEIRA; SANTANA, 2017; SANTANA et al., 2017a).

O coeficiente da elasticidade-renda do açaí foi de 0,4937 , indicando que aumentos de $10 \%$ na renda dos consumidores tendem a provocar reduções de 4,93\% na demanda de açaí fruto. Como o sinal do coeficiente foi positivo, trata-se de um bem normal. Este resultado foi menor do que o estimado por Santana (2013), da ordem de 0,733 , para as mesorregiões do Baixo Amazonas e Sudoeste Paraense.

A elasticidade cruzada da demanda do açaí com relação ao preço da castanha foi igual a 0,4294 , mostrando que a cada incremento de $10 \%$ no preço da castanha com casca, tende a produzir aumento na demanda de açaí fruto de 4,29\%, indicando substitutibilidade entre esses produtos. Ou seja, os intermediários tendem a fazer uma realocação dos produtos a serem comercializados para os mercados locais, dada sua capacidade para transportar o produto e a opção de obter maior retorno ou satisfação com a decisão. Este resultado demonstra que a análise dos produtos do extrativismo apresente nítido diferencial das análises tradicionais sobre o comportamento dos mercados de produtos.

Vale ressaltar que se trata da demanda de produtos do extrativismo em que a safra do açaí fruto coincide com a entressafra da castanha-do-Pará com casca. Assim, quando a demanda pelo açaí aumenta, por ter sido enquadrado como substituto da castanha e comercializado a um preço mais baixo, o consumo do produto no período da safra tende a aumentar, já que o preço está mais baixo e, concomitantemente, o preço do outro está relativamente mais alto, pois se encontra na entressafra, o que configura uma situação de substituição dos produtos por parte dos demandantes 
(SANTANA, 2016).

Analogamente, Nogueira e Santana (2009), ao analisarem o açaí e a bacaba e o efeito de substituição, destacaram que quando se inicia o período de entressafra do açaí, começa a safra de bacaba. Assim, o açaí apresenta elevação de preço (entressafra), ao passo que a bacaba apresenta preços mais baixos (safra), sendo então uma alternativa econômica viável ao consumidor. Com isto, observa-se que embora os produtos apresentem uma relação de substituição no mercado de varejo, em nível do extrativismo esta relação pode se inverter.

A elasticidade cruzada da demanda do açaí com relação ao índice de preço dos produtos da lavoura temporária foi igual a $-0,541$, mostrando que a cada incremento de $1 \%$ no preço desses produtos a ponto de representar uma mudança positiva no índice, tende a produzir uma redução na demanda do açaí fruto de 5,41\%, indicando uma relação de complementaridade no consumo.

Com relação ao ICMS, a elasticidade foi de $-0,622$, indicando que aumentos na carga tributária na comercialização dos produtos de açaí tendem a reduzir a demanda de açaí em 6,22\%. Isto revela que o ICMS exerce influência direta no consumo de açaí, considerando que um aumento nas taxas de impostos sobre o produto, a tendência é os consumidores demandarem menos açaí.

\subsection{A DEMANDA DE CASTANHA-DO-PARÁ}

O coeficiente de determinação ajustado para graus de liberdade mostra que 56,85\% das variações nas quantidades demandadas de castanha-do-Pará com casca foram explicadas diretamente por variações simultâneas no preço do açaí fruto, no índice de preços das lavouras temporárias, na renda per capita e no ICMS e, indiretamente, pelas variáveis instrumentais incluídas no modelo (Tabela 2). A estatística F, igual a 9,10, apresentou-se diferente de zero a $1 \%$ de probabilidade, atestando a hipótese alternativa de validação do modelo econométrico ao fenômeno estudado. Adicionalmente, a estatística $J$ de Hansen igual a 0,3245 confirmou a hipótese nula de que o vetor de variáveis exógenas e instrumentais é ortogonal aos erros e que o modelo está corretamente especificado. Com relação às estatísticas t, que testam a rejeição da hipótese nula de que a variável não influencia mudança na variável 
dependente, tem-se a aceitação da hipótese da adequação do modelo de efeitos fixos ao fenômeno estudado. A estatística de Durbin Watson indicou ausência de autocorrelação serial positiva de primeira ordem nos resíduos (Tabela 2). Em termos gerais, os resultados do modelo estimado estão consistentes com os argumentos apresentados no referencial teórico relativo à teoria do consumidor.

Os resultados da demanda por castanha-do-Pará com casca da Tabela 2 mostram que os sinais dos parâmetros de preço estão coerentes com a teoria do consumidor e são estatisticamente significantes, o que indica que as reações com relação a incrementos de preço do produto e de renda do consumidor são estabelecidas de forma inversa em relação ao preço e direta em relação à renda. Assim, os preços e a renda apresentaram correlações negativa e positiva, respectivamente, com as quantidades demandadas da castanha-do-Pará com casca. O coeficiente associado à variável ICMS apresentou um sinal negativo, mostrando uma relação inversa entre o aumento do imposto e a quantidade demandada do produto.

Tabela 2. Resultados da demanda de castanha-do-Pará com casca no Estado do Pará

\begin{tabular}{|c|c|c|c|c|}
\hline \multicolumn{5}{|c|}{ Variável Dependente: $\ln (\mathrm{QCP})$} \\
\hline Variável & Coeficientes & Desvio Padrão & Estatística-t & Probabilidade \\
\hline Constante & $-6,7581 * * *$ & 2,1734 & $-3,1095$ & 0,0028 \\
\hline $\ln (\mathrm{PAC})$ & $0,7149 * * *$ & 0,2342 & 3,0525 & 0,0033 \\
\hline $\ln (\mathrm{PCP})$ & $-0,2073^{*}$ & 0,1142 & $-1,8152$ & 0,0740 \\
\hline $\ln$ (Renda) & $0,9682 * * *$ & 0,2875 & 3,3679 & 0,0013 \\
\hline $\ln (\mathrm{PLT})$ & $1,0136 * *$ & 0,4762 & 2,1286 & 0,0370 \\
\hline $\ln (\mathrm{ICMS})$ & $-0,6572 * * *$ & 0,1953 & $-3,3656$ & 0,0013 \\
\hline R- Quadrado ajustado & 0,5685 & Média variavel depen & & 6,0217 \\
\hline Estatística - F & 9,1031 & $\begin{array}{l}\text { Desv.p. variavel } \\
\text { depend }\end{array}$ & & 1,4738 \\
\hline Prob (Estatist - F) & 0,0000 & Durbin-Watson & & 1,7962 \\
\hline
\end{tabular}

Fonte: Dados da pesquisa. ***Significativo a $1,0 \% ; * *$ Significativo a $5,0 \%$; * Significativo a $8,0 \%$. 
Com relação à relação entre o índice de preços das lavouras temporárias e as quantidades demandadas de castanha com casca, obteve-se um sinal positivo, indicando que há uma relação de substitutibilidade entre a demanda de castanha com casca e o agregado das lavouras temporárias das mesorregiões estudadas.

O coeficiente da elasticidade-preço da demanda foi igual a $-0,2073$, indicando que o produto é inelástico a preço. Assim, para um aumento de 10\% nos preços da castanha, a quantidade demandada tende a cair em 2,07\%. Este resultado está consistente com o coeficiente de -0,222, estimado por Santana (2015) para a região Norte no período de 1990 a 2010. O resultado da elasticidade-preço da castanha estimado por Santana (2013), para as mesorregiões do Baixo Amazonas e do Sudoeste Paraense, no período de 2000 a 2012, foi de -0,611.

O coeficiente da elasticidade-renda da castanha foi de 0,968 indicando que aumentos de $10 \%$ na renda dos consumidores incrementam 9,68\% a demanda de castanha-do-Pará, caracterizando o produto como um bem normal. Este resultado foi próximo do valor estimado por Santana (2015) para a região Norte, da ordem de 0,819 . Por sua vez, Santana (2013) encontrou um coeficiente de 1,085 para as mesorregiões do Baixo Amazonas e Sudoeste Paraense. Isto indica que as peculiaridades dos mercados locais influenciam nas relações de demanda dos produtos do extrativismo da Amazônia.

A elasticidade cruzada da demanda de castanha com casca em relação ao preço do açaí fruto foi igual a 0,7149 , mostrando que cada incremento de $10 \%$ no preço do açaí fruto, tende a produzir aumento na demanda de castanha com casca por parte dos agentes intermediários da comercialização de 7,14\%. Este resultado confirma que estes produtos apresentam relação de substitutibilidade como analisado anteriormente na demanda de açaí.

A elasticidade cruzada da demanda de castanha com casca em relação ao preço dos produtos das lavouras temporárias foi igual a 1,013, mostrando que a cada incremento de $10 \%$ no preço das lavouras temporárias, tende a produzir aumento na demanda de castanha com casca das mesorregióes analisadas de 10,13\%. Isto revela que a castanha com casca e as lavouras temporárias são fortes substitutos nas decisões de compra por parte dos agentes intermediários da comercialização.

A relação entre a demanda de castanha-do-Pará com casca e o ICMS apre- 
sentou uma elasticidade de $-0,6572$, indicando que incremento no imposto estadual em $10 \%$ tende a reduzir a demanda de castanha em $6,57 \%$. Portanto, a comercialização do produto, que é realizada por atravessadores em mais de $77 \%$ do total (SANTANA, 2016), é impactada com pela política de imposto sobre a circulação desse produto.

\section{CONSIDERAÇÕES FINAIS}

O açaí fruto das mesorregiões paraenses é inelástico a preço e, com base na elasticidade-renda, é um bem normal. A elasticidade cruzada indicou a castanha-do-Pará com casca como produto substituto do açaí e complementar da lavoura temporária.

A demanda de castanha-do-Pará com casca das mesorregiões paraenses é inelástica a preço e a renda, classificado como um bem normal. A elasticidade cruzada da demanda de castanha indicou uma relação de substituição com o açaí fruto e com lavoura temporária.

A variável ICMS apresentou impacto negativo e significativo sobre as demandas de açaí fruto e de castanha-do-Pará com casca das mesorregiões paraenses no período analisado.

\section{REFERÊNCIAS}

BALTAGI, B. H. Econometric analysis of panel data. 5. ed. John Wiley \& Sons, 2013.

IBGE - Instituto Brasileiro de Geografia e Estatística. Produção da Extração Vegetal e da Silvicultura. 2015. Disponível em: [www.sidra.ibge.gov.br/bda/acervo]. Acesso em: 06 mar. 2016.

IBGE - Instituto Brasileiro de Geografia e Estatística. (2015). Produção agrícola municipal, 2016. Disponível em: [www.sidra.ibge.gov.br/bda/acervo]. Acesso em: 15 mar. 2016.

IDESP - Instituto de Desenvolvimento Econômico, Social e Ambiental do Pará. Es- 
tatísticas. 2014. Disponível em: www.idesp.pa.gov.br. Acesso em: 10-12 mar. 2014.

KRAG, M. N.; SANTANA, A. C.; MARTINS, C. M.; VALE, R. S. Análise sistêmica do arranjo produtivo local da castanha-do-brasil na região da Calha Norte, Pará. Revista de Ciências Agrárias, v. 59, n. 2, p. 243-251, 2016.

MANKIW, N. G. Introdução à economia. São Paulo: Cengage Learning, 2009.

MARSHALL, A. Princípios de economia. São Paulo: Abril Cultural, 1982. 272p.

NOGUEIRA, A. K. M.; SANTANA, A. C. Análise de sazonalidade de preços de varejo de açaí, cupuaçu e bacaba no estado do Pará. Revista de Estudos Sociais, ano 11, n. 21, v. 1, p. 7-22, 2009.

NOGUEIRA, A. K. M.; SANTANA, A. C. Benefícios socioeconômicos da adoção de novas tecnologias no cultivo do açaí no Estado do Pará. Revista Ceres, v. 63, n. 1, p. 1-7, 2016.

NOGUEIRA, A. K. M.; SANTANA, A. C.; GARCIA, W. S. A dinâmica do mercado de açaí fruto no Estado do Pará: de 1994 a 2009. Revista Ceres. Viçosa, v. 60, p. 324-331, 2013.

PINDYCK, R. S.; RUBINFELD, D. L. Microeconomia. São Paulo: Pearson, 2010.

SAHA, D.; SUNDRIYAL, R. C. Utilization of nontimber forest products in humid tropics: Implications for management and livelihood. Forest Policy and Economics. Amsterdam, v. 14, n. 1, p. 28-40, 2012.

SANTANA, A. C.; KHAN, A. S. Custo social da depredação florestal no Pará: o caso da castanha-do-brasil. Revista de Economia e Sociologia Rural, v. 30, n. 3, p. 253269, 1992.

SANTANA, A. C. Elementos de economia, agronegócio e desenvolvimento local. Belém: UFRA, 2005, v. 500. 197p.

SANTANA, A. C. Estudo exploratório das cadeias produtivas do açaí e da castanha-do-brasil na Amazônia brasileira. Belém: IPAM, 2016.

SANTANA, A. C. Mercado de produtos agropecuários e florestais dos polos de 
Altamira, Itaituba e Santarém, estado do Pará. Belém: UFRA/FUNPEA/PAM, 2013.

SANTANA, A. C. Recent changes in the relations of Brazilian meat demand system. Revista de Economia e Sociologia Rural, v. 37, n. 2, p. 161-184, 1999.

SANTANA, A. C. Valoração de produtos florestais não madeireiros da Amazônia: o caso da castanha-do-brasil. Tese (Professor Titular). Universidade Federal Rural da Amazônia, 2015.

SANTANA, A. C.; COSTA, F. A. Mudanças recentes na oferta e demanda do açaí no Estado do Pará. In: SANTANA, A. C.; CARVALHO, D. F.; MENDES, F. A. T. Análise sistêmica da fruticultura paraense: organização, mercado e competitividade empresarial. Belém: Banco da Amazônia, 2008, p. 205-226.

SANTANA, A. C.; GOMES, S. C. Mercado, comercialização e ciclo de vida do mix de produtos do açaí no Estado do Pará. In: CARVALHO, D. F. (Ed.). Ensaios selecionados sobre a economia da Amazônia nos anos 90. Belém: Universidade da Amazônia, 2005.

SANTANA, A. C.; SANTANA, Á. L.; GOMES, S. C.; SANTANA, Á. L.; NOGUEIRA, A. K. M.; OLIVEIRA, C. M.; SANTOS, M. A. S. Evidências do mercado de produtos da pequena produção na região da Transamazônica e BR-163 no estado do Pará, Revista de Estudos Sociais, v. 17, n. 2, p. 186-215, 2015.

SANTANA, A. C.; SANTANA, Á. L.; SANTANA, Á. L.; SANTOS, M. A. S.; OLIVEIRA, C. M. Análise discriminante múltipla do mercado varejista de açaí em Belém do Pará. Revista Brasileira de Fruticultura. São Paulo, v. 36, p. 532-541, 2014.

SANTANA, A. C.; SANTANA, Á. L.; SALOMÃO, R. P.; SANTANA, Á. L.; COSTA, N. L.; SANTOS, M. A. S. O Custo Socioambiental da Destruição de Castanheiras (Bertholletia excelsa) no Estado do Pará. Revista de Estudos Sociais, v. 18, n. 1, p. 3-21, 2016.

SANTANA, A. C.; SANTANA, Á. L.; SANTANA, Á. L. Açaí pulp demand in the retail Market of Belém, State of Pará. Revista Brasileira de Fruticultura, v. 39, n. 1, p. $1-7,2017 \mathrm{a}$.

SANTANA, A. C.; SANTANA, Á. L.; SANTANA, Á. L.; MARTINS, C. M. Valoração e sustentabilidade da castanha-do-brasil na Amazônia. Revista de Ciências Agrárias, v. 60, n. 1, p. 77-89, 2017b. 
SILVA, A. A.; SANTOS, M. K. V.; GAMA, J. R. V.; NOCE, R.; LEÃO, S. Potencial do Extrativismo da Castanha-do-Pará na Geração de Renda em Comunidades da Mesorregião Baixo Amazonas, Pará, Floresta e Ambiente, v. 20, n. 4, p. 500-509, 2013.

VARIAN, Microeconomia: princípios básicos. Rio de Janeiro: Campus, 2012. 807p.

Recebido em:09/03/2017 Aceito em: 05/11/207 